\title{
A experiência humana da morte e a esperança cristã no testemunho de Edith Stein
}

\author{
The human experience of death and the Christian hope \\ in the testimony of Edith Stein
}

\author{
Leomar Antonio Brustolin*, Patrícia Espíndola de Lima Teixeira**
}

\begin{abstract}
RESUMO
Consciente de sua finitude, a pessoa humana traz em si a vontade de eternidade. Com a percepção de ser finito, o ser humano compreende que o viver comporta o morrer. Em diferentes instâncias, a sociedade contemporânea tem evitado a consciência de finitude, gerando seres que agem como ilimitados. A busca pela significância da morte, provoca também, o questionamento sobre o sentido da vida. O presente artigo aborda a experiência humana como uma pedagogia, um caminho condutor ao sentido da morte à luz do cristianismo. Para isso, analisa na essência cristã o valor da conversão, da comunhão e da esperança eterna. Como ilustração desse processo, o texto faz uma breve investigação sobre a experiência da morte no testemunho de conversão e martírio da filósofa alemã Edith Stein (1891-1942). Edith Stein tem sua vida interrompida em Auschwitz durante a II Guerra Mundial. O híbrido vida e obra steiniana carrega a marca do período entre guerras, apontando para o valor inegociável da vida humana e pela verdade da fé. Unida a cruz de Cristo, a quem compreendeu como o Verbo Encarnado, Morto e Ressuscitado, percorreu o caminho do sentido com a certeza de que a glória da ressurreição, passa pelo significado salvífico da cruz.
\end{abstract}

Palavras-Chave: Morte. Finitude. Eternidade. Esperança Cristã. Edith Stein.

\section{ABSTRACT}

Aware of its finitude, the human person carries within himself the will of eternity. With the perception of being finite, the human being understands that living entails dying. In different instances, contemporary society has avoided awareness of finitude, generating beings who act as unlimited. The search for the significance of death also provokes the questioning of the meaning of life. The present article addresses the human experience as pedagogy, a leading way to the meaning of death in the light of Christianity. In order to do this, it analyzes in the Christian essence the value of conversion, communion and eternal hope. As an illustration of this process, the text briefly investigates the experience of death in the testimony of conversion and martyrdom of the German philosopher Edith Stein (1891-1942). Edith Stein has had her life interrupted at Auschwitz during World War II. The hybrid of Stein's life and work carries the mark of the period between wars, pointing to the nonnegotiable value of human's life and the truth of faith. United to the cross of Christ, comprehended as the Incarnated, Dead and Resurrected went along a meaningful path with the certainty that the glory of the resurrection passes through the saviour meaning of the cross.

KEYWORDS: Death. Finitude. Eternity. Christian Hope. Edith Stein.

* Doutor em Teologia pela Pontificia Università San Tommaso, Roma, Itália. Professor titular da Pontifícia Universidade Católica do Rio Grande do Sul, Brasil. E-mail: <leomar.brustolin@pucrs.br>.

** Mestra em Teologia Sistemática pela Pontifícia Universidade Católica do Rio Grande do Sul, Brasil. Possui também especialização em Psicopedagogia Clínica e Institucional pela Faculdade Porto-Alegrense. E-mail: <pp.patriciateixeira@gmail.com>. 


\section{INTRODUÇÃO}

Debaixo do céu há momento para tudo, e tempo certo para cada coisa: Tempo para nascer e tempo para morrer. Tempo para plantar e tempo para arrancar a planta. (Eclesiastes 3,1-2)

O ser humano é a única criatura que tem consciência de sua finitude. Sabe que o viver comporta o morrer. A consciência da mortalidade leva a pessoa ao desejo de imortalidade. É uma inquietude que permanece, refratando as hipóteses de um dia a pessoa não mais existir.

Em diferentes épocas, povos de diversas culturas construíram diferentes concepções sobre o sentido da morte e a possibilidade de existir após esta vida. Basearam-se em percepções da natureza, em revelações sobrenaturais, no desejo de transcendência, em livros sagrados ou em mensagens de profetas e mestres. As religiões nascem do encontro do humano com o divino para estabelecer um sentido para viver, partindo de uma releitura sobre o morrer e possibilitar novas escolhas para enfrentar a vida que tende à morte.

Refletir sobre a morte é refletir sobre a vida. O tema da morte é visto como um tabu, na maioria das vezes ocultado e impronunciável, mas cada vez mais a comunicação é necessária para o seu enfrentamento. Todo o ser humano naturalmente sabe que um dia morrerá, mas está de tal forma envolvido com a vida, que não pensa a respeito da própria morte, porque a morte é sempre a do outro, do estranho, de alguém fora do seu próprio eu.

O avanço tecnológico e científico favorece o desviar-se das questões relativas à finitude humana. A morte, quando pronunciada, desperta curiosidade, desconforto, emoções, reflexões e medo. Por isso, muitas vezes, a morte é mascarada. O ser humano contemporâneo "ao mesmo tempo em que sabe de sua finitude de forma racional e consciente, vive toda a sua existência com a morte presente em seus sonhos e fantasias. Durante toda sua existência o ser humano tenta driblar esse saber, essa consciência e age como imortal". ${ }^{1}$

Este artigo considera essa realidade e propõe uma reflexão sobre a experiência humana diante da morte, analisando o testemunho de Edith Stein (1891-1942). Stein, fenomenóloga alemã com ascendência judaica, convertida ao cristianismo, tornou-se monja carmelita e importante mística católica. Morta nas câmaras de gás em Auschwitz, durante a II Guerra Mundial, foi canonizada e proclamada Santa Mártir da Igreja Católica pelo Papa João Paulo II. Seu processo de conversão apresenta forte adesão à pessoa de Jesus. O Cristo crucificado e ressuscitado, contemplado por Edith, sobretudo na significação da cruz, remete à esperança cristã na eternidade em unidade com Deus, partindo de uma profunda vida de sabedoria, oração e exercício de amor-doação aos demais.

\section{A MORTE COMO UMA PEDAGOGA}

Morrer faz parte do viver. Diante de uma história de vida avançada esta afirmação tende a ser melhor compreendida. Vê-se, possivelmente, como cumprimento de uma missão; um itinerário que se conclui e deixa seus frutos. Porém, diante de uma vida interrompida na infância, no vigor juvenil ou no dinamismo da vida adulta, tal afirmação

${ }^{1}$ KOVÁCS, M.J. Morte e desenvolvimento humano, p. 24. 
rompe a lógica natural e desconcerta. A morte assim intimida, gera compaixão ou até revolta.

No processo de elaboração da morte de um ente querido, a pessoa encontra-se convocada subjetivamente a dar uma resposta. Não é possível permanecer alheia, sem que haja alguma consequência. É preciso reaprender a viver, refazer conceitos, planejamentos, hierarquizar os valores e conviver com a ausência. Neste sentido a vivência do luto tem fundamental importância de elaboração psíquica, ressignifição dos fatos, compreensão dos afetos e reinserção social. Em contrapartida, a submissão diante da morte, a negação do luto ou a falta de resiliência perante a dor vivida, tende a gerar um ser resignado, árido, operativo, austero e até descrente. De certa forma, corre-se o risco de "perder" a vida em vida, justamente pelas inquietantes questões que surgem. Como seguir quando aqueles que amamos já não estão conosco? Como manter a vivacidade quando a dor da ausência do ser amado insiste em apontar para um abismo na relação vida e morte? É possível reencontrar a alegria carregando a dor da morte daqueles que amamos? E se for possível, temos esse direito?

Em termos comunitários, se não somos nós a vivenciarmos a morte de alguém, certamente, em algum momento, estaremos na situação de solidariedade com quem vive tal dor. Como empatizar com a situação de uma mãe que ao enterrar um filho vê-se com a "espada de dor que lhe transpassa a alma"? Com um jovem que torna-se órfão ao ter os pais mortos pela violência? Com aquele que acompanha a morte lenta do irmão consumido pelo câncer? Ao esposo que vê sua esposa morrer de forma fulminante enquanto faziam seus planos cotidianos? São muitas as histórias, cada uma com sua particularidade e todas com semelhante angústia. A morte nos coloca diante do outro e diante nós mesmos, e nos recorda: um dia nos alcançará.

No entanto, a pergunta proposta neste texto vai além das interrogativas latentes. É preciso ir além da dor em busca de uma resposta mais consciente: morrer é de fato perder?

Para isso, busca-se na essência cristã o significado da morte. A ótica cristã católica tanto sobre a vida, quanto sobre a morte, confere uma significação profunda do valor da conversão e da comunhão. A vida não é um bem provisório e a morte não é o fim de tudo. Assim, tanto como é preciso aprender a viver, é preciso aprender a significar a morte em uma decisão de fé. Se não há beleza na morte, há beleza na fé livre de quem mantém a decisão de ir ao encontro do seu sentido salvífico; há beleza no gesto fraterno de "enxugar o rosto daquele que sofre" e "auxiliar no esforço de quem carrega a pesada cruz" , em um ato de esperança, comunhão e acolhimento ao amor que ensina a ir em busca dos bens eternos.

\section{O TESTEMUNHO DE EDITH STEIN DIANTE DA MORTE - UM PROCESSO DE CONVERSÃO}

No processo pedagógico de aquisição do sentido cristão da esperança eterna, Edith Stein, filósofa alemã, foi alguém que diante da morte, encontrou o Sentido da vida. A agudez de pensamento antropológico de Edith entrelaçou-se diretamente com sua experiência. ${ }^{3}$ Nascida em 12 de outubro de 1891, Stein nasceu na Festa da Expiação,

\footnotetext{
${ }^{2}$ Comparação com a ordem recebida por Simão Cirineu em auxiliar Jesus no carregamento de sua cruz. Cf. Lc 23, 26; Mc 15, 20b; Mt 27, 31b.

${ }^{3}$ Em ALFIERI, Francesco. Pessoa humana e singularidade em Edith Stein. São Paulo: Perspectiva, 2014, encontra-se a inserção de uma cronologia breve da vida e obra de Edith Stein. Tal cronologia associada aos escritos autobiográficos de Edith Stein, serviram como aporte para o contexto biográfico desenvolvido no presente artigo.
} 
uma das principais festas do judaísmo. ${ }^{4}$ Em seu processo de vida e morte é possível inferir o cumprimento do que se comemorava no dia de seu nascimento, pois diante da morte eminente ela mesma se fez oferta, como holocausto, unida ao povo do qual era proveniente. Porém, para chegar à oferta livre de si, foi preciso aprender não só a viver, mas também, como morrer.

Em seu primeiro encontro com a morte, a pequena Edith Stein, então com 2 anos de idade, ficou órfã de pai. O senhor Siegfried Stein foi encontrado morto durante uma viagem de negócios. ${ }^{5}$ Sua mãe assumiu a empresa da família, o cuidado dos onze filhos e o zelo por sua educação na fé judaica. Edith cresceu percebendo a coragem e fortaleza da mãe, mas também, viu a consequência da marca austera e firme assumida na personalidade materna. A senhora Augusta educou os filhos com tenacidade para que rigorosamente observassem os ritos da religião. "Consequentemente, até a alegria das crianças era moderada pela austeridade de um "sacro temor a Deus". ${ }^{6} \mathrm{Na}$ adolescência, Edith passou por uma profunda crise de fé, afastando-se do judaísmo e consequentemente, da educação materna. Dedicou-se ao saber humano e as verdades científicas, passando a declarar-se ateia. Partiu de sua cidade natal, Breslau, para Gotinga onde estudou e colaborou diretamente com Edmund Husserl (1859-1938), participando da escola fenomenológica alemã. ${ }^{7}$ Sobre esse período, a filósofa afirmou ter deixado conscientemente de rezar e que a busca pela verdade era sua única prece.

Seu segundo encontro com a morte ocorreu na I Guerra Mundial. Como universitária, se voluntariou como enfermeira da Cruz Vermelha, convivendo com o sofrimento e a morte dos doentes de tifo. No mesmo período, Edith enfrentou a morte de seu grande amigo, o filósofo judeu, convertido ao cristianismo, Adolf Reinach. O filósofo admirado por Stein por seu conhecimento e ética, morreu no front de batalha. Diante do desconcerto interior que sucedeu em si com a perda de alguém tão caro, inquietou Edith a forma serena e nobre com que a esposa de Reinach, também cristã, reagiu ao enfrentar a dor. ${ }^{8}$ Além disso, Stein organizou postumamente, os escritos e pesquisa do filósofo. Edith percebeu assim, o valor dos frutos de continuidade originados de uma vida dedicada. Mesmo já não estando no mundo, a vida deixa impressões aos demais e isto a torna presente nos dons ofertados. Posteriormente, Edith Stein chegou a afirmar que naquela situação, viveu seu primeiro encontro com a Cruz de Cristo:

O meu primeiro encontro com a Cruz, a minha primeira experiência da força divina que da Cruz emana e se comunica a todos os que a abraçam. Pela primeira vez, me foi dado contemplar em toda a sua luminosidade a realidade da Igreja, nascida da Paixão salvadora de Cristo, na sua vitória sobre a morte. Foi esse o momento em que a minha incredulidade caiu, ofuscou-se o hebraísmo e Cristo ergueu-se luminoso diante do meu olhar. Cristo no mistério de sua cruz ${ }^{9}$

\footnotetext{
${ }^{4}$ A festa da Expiação (ou da Reconciliação) ocorria uma só vez no ano, onde o Sumo Sacerdote adentrava o Santo dos Santos para fazer a oferta em expiação às infidelidades do povo. O nome de Deus era invocado nesta única vez, depois do Sumo Sacerdote aspergir o propiciatório do Santo dos Santos com o sangue do sacrifício. A partir da fé judaica, na fé católica, São Paulo nos diz que Cristo foi destinado por Deus como instrumento de propiciação, por seu próprio Sangue "era Deus que em Cristo reconciliava consigo o mundo".

${ }^{5}$ STEIN, E. Escritos autobiográficos y cartas. p. 175.

${ }^{6}$ Edith Stein, citada por GARCIA, J.T.; SCIADINI, P. Edith Stein: Holocausto para seu povo, p. 24.

${ }^{7}$ STEIN, E. Escritos autobiográficos y cartas. p. 345. Trata-se de um importante grupo de estudo e pesquisa com visão multidisciplinar articulada a fenomenologia de Husserl. Dentre os principais fenomenólogos membros do chamado Círculo de Gotinga ao qual Edith Stein integra-se: Theodor Conrad-Martius (1861-1969), Hedwig Conrad-Martius (1888-1966), Hans Lipps (1889-1941), Adolf Reinach (1883-1917), Dietrich von Hildebrand (1889-1977), Roman Ingarden (1893-1970), Max Scheler (1874-1928), entre outros.

${ }^{8}$ STEIN, E. Escritos autobiográficos y cartas. p. 53.

${ }^{9}$ GARCIA, J.T.; SCIADINI, P. Edith Stein: Holocausto para seu povo, p. 13.
} 
As experiências citadas fizeram com que novamente Stein se dispusesse a um encontro com Deus, mas não mais no judaísmo, e sim no cristianismo. Sua busca incessante em conhecer a verdade apontou-a para os escritos cristãos. Foi Max Scheler (1874-1928), a quem considerava um "fenômeno da genialidade" que a influenciou em conhecer o cristianismo. ${ }^{10}$ Stein leu o Novo Testamento e outros registros cristãos, até que em 1921, teve acesso ao Livro da Vida de Santa Teresa de Jesus. Leu-o com intensidade e de forma contínua, declarando ao final que ali estava a verdade do qual buscava. Stein decidiu, assim, receber o batismo na fé católica, aos 30 anos. Aos 42 anos, abraçou a vocação religiosa na Ordem Carmelita, seguindo a vida contemplativa e também, seu trabalho intelectual. ${ }^{11}$

Aponta-se aqui um terceiro encontro com a morte: sua própria prisão e martírio. Com a ocupação da Holanda na $2^{\text {a }}$ Guerra Mundial pela Alemanha nazista, aconselhada por seus superiores para transferir-se a outro Carmelo em região mais segura, Stein decidiu permanecer em Echt, apesar de sua ascendência judaica torná-la vulnerável. O episcopado holandês manifestou-se publicamente contrário ao regime nazista, onde através de uma Carta Pastoral denunciava a deportação e violência contra judeus. Em represália à Igreja Católica na Holanda, além de judeus, foram perseguidos também os judeus convertidos ao catolicismo. Assim, em 2 de agosto de 1942, o Carmelo de Echt foi invadido pela Gestapo. Edith Stein foi capturada e levada ao campo de extermínio de Auschwitz, juntamente com sua irmã, morrendo na câmara de gás.

Poucos dias antes da sua deportação, a quem lhe oferecia possibilidade de salvar a vida, a religiosa respondera: "Não o façais! Por que deveria eu ser excluída? A justiça não consiste acaso no facto de eu não obter vantagem do meu batismo? Se não posso compartilhar a sorte dos meus irmãos e irmãs, num certo sentido a minha vida é destruída." ${ }^{12}$

O último registro de Edith Stein consta em um pequeno papel encontrado no caminho para Auschwitz, com a afirmação de que seguia em direção à Polônia com seu povo. O horror da prisão nazista foi relatado por diferentes sobreviventes ao longo dos anos posteriores. Porém diante da eminência da morte, mesmo em condição indigna, testemunhas relatam os serviços e cuidados prestados por Edith às demais prisioneiras e seus filhos até o momento de sua oblação.

Cerca de oito anos após a morte da monja carmelita, a forma concisa da declaração oficial contrapõe-se à profundidade da oferta de vida. Em 16 de fevereiro de 1950, o principal jornal holandês trazia como nota do Ministério da Justiça o número de prisioneira de Stein, 44.074, e a declaração de que Edith Teresa Hedwig Stein, nascida em 12 de outubro de 1891 em Breslau, havia sido morta no dia 9 de agosto de 1942.

Beatificada pelo Papa João Paulo II em 1 de maio de 1987 e, em 11 de outubro de 1998, foi canonizada pelo mesmo Papa. Em 1999, João Paulo II declarou-a como co-padroeira da Europa. Em sua homilia na cerimônia de canonização de Edith Stein, o Papa João Paulo II, proferiu:

Santa Teresa Benedita da Cruz conseguiu compreender que o amor de Cristo e a liberdade do homem se entretecem, porque o amor e a verdade têm uma relação intrínseca. (...). Todavia, a verdade e o amor têm necessidade uma do outro. A Irmã Teresa Benedita é testemunha disto. "Mártir por amor", ela deu a vida pelos seus amigos e no amor não se fez superar por ninguém. Ao mesmo

${ }^{10}$ STEIN, E. Escritos autobiográficos y cartas. p. 365-366.

${ }^{11}$ STEIN, E. Escritos autobiográficos y cartas. p. 493.

${ }^{12} \mathrm{Cf}$. JOÃ̃ PAULO II. Homilia na Cerimônia de Canonização de Edith Stein. 
tempo, procurou com todo o seu ser a verdade, da qual escrevia: "Nenhuma obra espiritual vem ao mundo sem grandes sofrimentos. Ela desafia sempre o homem inteiro". A Irmã Teresa Benedita da Cruz diz a todos nós: Não aceiteis como verdade nada que seja isento de amor. E não aceiteis como amor nada que seja isento de verdade! Enfim, a nova Santa ensina-nos que o amor a Cristo passa através da dor. Quem ama verdadeiramente, não se detém diante da perspectiva. (...). Pouco a pouco, o mistério da Cruz impregnou toda a sua vida, até a impelir rumo à oferta suprema. Como esposa na Cruz, a Irmã Teresa Benedita não escreveu apenas páginas profundas sobre a "ciência da cruz", mas percorreu até ao fim o caminho da escola da Cruz. ${ }^{13}$

A dor da mártir uniu-se a dor daqueles aos quais considerou seus irmãos. Consciente de que Cristo veio ao mundo por todos os povos, a todos redimiu e tem seus caminhos para alcançar a humanidade na atual etapa escatológica da história da salvação. ${ }^{14}$ Uniuse também, ao que assumiu como bendita cruz de Jesus, que lhe assegurou a misteriosa fecundidade do Amor, com a coragem de se ofertar até o fim e com o qual havia se identificado em seu nome religioso: Teresa Benedita da Cruz.

\section{A ESPERANÇA CRISTÃ NA ETERNIDADE INSPIRADA POR SANTA TERESA BENEDITA DA CRUZ}

Santa Teresa Benedita da Cruz tem seu nome registrado entre os mártires da Igreja. Em seu martírio, testemunhou em vida a suprema adesão à verdade de fé e foi morta justamente pela causa de Cristo. Em Stein, podemos concluir o quanto foi inegociável o valor que deu a vida humana. Morreu unida a cruz de Jesus, atribuindo um novo sentido a morte, tornou-se um "Outro Cristo", o Alter Christus ao qual todo cristão é chamado a ser.

Com isto, a vida e os escritos de Edith Stein, conduzem ao Mistério Pascal de Cristo, como eixo articulador entre o viver e o morrer. Stein depositou sua fé em Jesus como Verbo Encarnado, Morto e Ressuscitado. Como homem que era, Jesus viveu a morte própria da condição humana. No entanto, a oferta de Cristo na Cruz imprimiu a morte um novo significado. Em Cristo, a morte é transformada no ato de amor redentor.

A compreensão que Edith Stein apresenta no processo de sua vida e obra, confere o amor como um "dom de si ao bem". ${ }^{15}$ Acentua ainda o amor como máxima realização do ser. Stein reconhece no Crucificado-Ressuscitado, o ser divino doando-se a si mesmo em favor de todos: "o amor é o ser de Deus, a vida de Deus, a essência de Deus". ${ }^{16}$ O Deus-Amor que se doa até o fim, fez da morte uma passagem para a eternidade. Ressurrecto dos mortos, vivo para sempre, Stein reconhece o Cristo que abriu para toda a humanidade a possibilidade de salvação e revelou: a plenitude passa pela cruz.

No sofrimento e morte de Cristo, nossos pecados forma consumidos pelo fogo. Se aceitarmos isso na fé e se numa entrega de fé, acolhermos o Cristo inteiro, ou seja, se escolhermos e percorrermos o caminho do seguimento de Cristo, então Ele nos conduzirá pelo seu sofrimento e cruz para a glória da ressurreição ${ }^{17}$

Assim, volta-se a questão provocativa do início deste texto: morrer é de fato perder?

\footnotetext{
${ }^{13}$ JOÃO PAULO II. Homilia na Cerimônia de Canonização de Edith Stein.

${ }^{14}$ ALES BELLO, A. Edith Stein: A Paixão pela Verdade. p. 21.

${ }^{15}$ STEIN, E. Ser finito y ser eterno. Ensayo de una ascensión al sentido del ser. p. 367.

${ }^{16}$ STEIN, E. Ser finito y ser eterno. Ensayo de una ascensión al sentido del ser. p. 367.

${ }^{17}$ Edith Stein, citada por SCIADINI, P. Edith Stein, na força da cruz, p. 86.
} 
O fim da peregrinação terrestre se dará a toda à pessoa, porém para aqueles que estiverem unidos a Cristo, está à garantia da graça eterna. Segundo, a Carta Encíclica Spe Salvi, a verdadeira fisionomia da esperança cristã remete:

A vida, no verdadeiro sentido, não a possui cada um em si próprio sozinho, nem mesmo por si só: aquela é uma relação. E a vida na sua totalidade é relação com Aquele que é a fonte da vida. Se estivermos em relação com Aquele que não morre, que é a própria Vida e o próprio Amor, então estamos na vida. Então "vivemos". ${ }^{18}$

Assim, estar em Deus, é de fato encontrar a fonte de Vida: "Os que morrem na graça e na amizade de Deus, e que estão totalmente purificados, vivem para sempre com Cristo. São para sempre semelhantes a Deus, porque o veem "tal como Ele é" (1Jo 3,2), face a face $(1$ Cor 13, 12)."19

$\mathrm{Na}$ consciência da morte enquanto passagem para a graça eterna, estar em Deus é estar pleno. Assim, mesmo diante de uma morte trágica ou inesperada, na abreviação da vida em pleno exercício, é possível encontrar o valor salvífico e o consolo em Deus. A superabundância do amor de Cristo compreende a dor da morte: o mistério de comunhão dos homens à Cristo, em Cristo e por Cristo vai além do alcance da razão humana: "O que os olhos não viram, os ouvidos não ouviram e o coração do homem não percebeu, isso Deus preparou para aqueles que o amam" (1Cor 2,9).

Na compreensão do gesto oblativo de Jesus que se entregou até o fim pelos seus, ainda como garantia da salvação, em Cristo, a esperança na eternidade confere uma certeza além. Para aquelas pessoas que porventura morrerem na amizade e graça de Deus, mas que necessitam reparar suas faltas e culpas, o purgatório apresenta-se como oportunidade de purificação, "a fim de obter a santidade necessária para entrar na alegria do Céu." 20

No exercício de caridade fraterna, toda pessoa é chamada a fazer parte do povo de Deus e corpo místico de Cristo, ao qual é convidada a viver a comunhão dos santos. Aqueles que morreram na graça, os que mortos ainda terminam sua purificação e aqueles que peregrinam na terra, formam unidade a recorrer ao amor misericordioso de Deus, e por meio do Espírito Santo, santificam-se, tornando-se intercessores uns dos outros, em uma troca de bens. A confiança na comunhão dos santos remete diretamente a segurança de que, como peregrinos na terra, vive-se a unidade através de Cristo, com todos aqueles que já partiram, ainda que cedo, para a eternidade. Assim como Jesus se fez Pessoa-Dom, todos, em cooperação com a graça, podem tornar-se dom aos demais, sobretudo enquanto espera-se a morte da morte, a ressurreição final na parusia de Cristo.

A esta verdade, Edith Stein nos conduz. Em sua peregrinação, deixa-nos Santa Teresa Benedita da Cruz a beleza de uma vida fecunda de entrega a Deus, comunhão com o próximo e compreensão sobre a verdade de si mesma. Resgata em seus estudos sobre a obra de João da Cruz, a compreensão de Deus como "o ponto de repouso da alma". ${ }^{21}$ Insiste no valor da interioridade para a experiência dos mistérios da fé. Segundo Stein, o sentido da existência humana - e portanto de sua finitude e eternidade - encontra-se na união com Deus no íntimo da alma humana. ${ }^{22}$

\footnotetext{
${ }^{18}$ BENTO XVI. Carta Encíclica Spe Salvi. 27.

${ }^{19}$ CATECISMO DA IGREJA CATÓLICA, 1023.

${ }^{20}$ CATECISMO DA IGREJA CATÓLICA, 1030.

${ }^{21}$ STEIN, E. A ciência da cruz. Estudo sobre São João da Cruz. p. 129.

${ }^{22}$ ALES BELLO, A. Edith Stein: a paixão pela verdade. p. 40.
} 
Para tanto, Edith Stein versa sobre a necessidade da fé pessoal em uma decisão definitiva que "só pode provir do íntimo; assim, (...) o que talvez seja impossível em termos naturais - necessita de um necessário reerguimento". ${ }^{23}$ As convicções desta santa mártir conduzem ao valor da esperança na alegria eterna: "paciência, perseverança, constância. Este saber esperar, suportando pacientemente as provas, é necessário para o crente poder obter as coisas prometidas". ${ }^{24}$

Consciente da situação de seu povo, dos malefícios gerados por seus algozes, da necessidade da vida da Igreja e de cada pessoa em particular do qual conviveu, em seu testamento espiritual revela o sentido que deu a vida e a morte:

Desde já, aceito a morte que Deus me destinou, enfrentando-a com alegria, em perfeita submissão à sua santíssima vontade. Peço o Senhor que aceite minha vida e minha morte para sua glória e louvor, por todas as necessidades (...) da Igreja (...) e para que o Senhor seja aceito pelos seus, e seu Reino venha em glória, pela salvação da Alemanha e pela paz no mundo; enfim pelos meus parentes vivos e falecidos, e por todos os que Deus me deu: que nenhum deles se perca. ${ }^{25}$

Assim foi com Edith. Encontrou no "Homem das dores", que assumiu sobre si os sofrimentos físicos e morais dos homens de todos os tempos, para que estes possam encontrar no amor o sentido salvífico dos próprios sofrimentos e respostas válidas para todas as suas interrogações. ${ }^{26}$

A Cruz de Cristo projeta a luz salvífica de um modo assim tão penetrante sobre a vida do homem e, em particular, sobre o seu sofrimento, porque, mediante a fé, chega até ele juntamente com a Ressurreição: o mistério da paixão está contido no mistério pascal. As testemunhas da paixão de Cristo são, ao mesmo tempo, testemunhas da sua Ressurreição. ${ }^{27}$

Atraída profundamente pela Cruz de Cristo, contemplada como sinal supremo de gesto empático de Deus que se doa à humanidade e a cada pessoa em particular, em Edith Stein encontra-se o testemunho manifestado, revelando que o verdadeiro sofrimento, a verdadeira angústia, o real perecer, não está na morte em si, mas está em perder a vida eterna.

\section{CONSIDERAÇÕES FINAIS}

Em Stein, a beleza da Verdade precisa ser reconhecida pelas pessoas. A verdadeira ciência emana da cruz. Por trás de toda a verdade e de toda a ciência está a Pessoa Divina encerrando e transcendendo em si os valores da eternidade e dispondo à pessoa humana. Stein reconheceu-se como um ser capaz de Deus, cristificou-se não por força própria, mas porque encontrou na pessoa de Jesus Cristo, o divino que se tornou humano. Com isso, o testemunho steiniano impele toda a pessoa a pensar na morte; e ao pensar na morte, deveria reportar-se à vida, buscando viver uma vida bem vivida, de forma a expressar a beleza do amor-doação, para que quando a morte chegar, encontre o ser com

\footnotetext{
${ }^{23}$ STEIN, E. A ciência da cruz. Estudo sobre São João da Cruz. p.138.

${ }^{24}$ BENTO XVI. Carta Encíclica Spe Salvi. n.9

${ }^{25}$ STEIN, E. Escritos autobiográficos y cartas. p. 515-516.

${ }^{26}$ JOÃO PAULO II. Carta Apostólica Salvifici Doloris. n. 17.

${ }^{27}$ JOÃO PAULO II. Carta Apostólica Salvifici Doloris. n. 21.
} 
a esperança de receber a justiça do Justo Juiz ao qual tornou-se próxima ao "combater o bom combate e guardar a fé" (cf. 2 Tim 4,7-8) em seu itinerário de vida.

No Cristianismo, a morte é compreendida a partir do Crucificado. O Deus cristão se revela plenamente na cruz de Jesus Cristo. Inicialmente, se pode pensar que Deus e a morte são duas realidades incompatíveis. Isso, porém, não significa que sejam incomunicáveis.

$\mathrm{Na}$ experiência de Edith Stein compreende-se como os místicos cristãos atribuem novo sentido ao morrer. Para eles a experiência da morte pode ser ressignificada a partir da união do ser humano com Cristo. Quem faz essa experiência ao longo da vida compreende, de forma antecipada e limitada, a promessa de salvação da morte.

\section{REFERÊNCIAS}

A BÍBLIA de Jerusalém. São Paulo: Paulus, 1981.

ALES BELLO, Angela. Edith Stein: a paixão pela verdade. Curitiba: Juruá, 2014.

ALFIERI, Francesco. Pessoa humana e singularidade em Edith Stein. São Paulo: Perspectiva, 2014.

BENTO XVI. Carta Encíclica Spe Salvi. Roma, 30/11/2007. Disponível em: <http://w2.vatican.va/ content/benedict-xvi/pt/encyclicals/documents/hf_ben-xvi_enc_20071130_spe-salvi.html>.Acesso em: 28 out. 2017 .

BRUSTOLIN, Leomar Antônio. Quando Cristo vem... a parusia na escatologia cristã. São Paulo: Paulus, 2001.

CATECISMO DA IGREJA CATÓLICA. São Paulo: Loyola, 1999.

GARCIA, Jacinta Turolo; SCIADINI, Patricio. Edith Stein: Holocausto para seu povo. São Paulo: Loyola, 1987.

JOÃO PAULO II. Carta Apostólica em forma de "Motu Próprio” Spes Aedificandi para Proclamação de Santa Brígida da Suécia, Santa Catarina de Sena e santa Benedita da Cruz Co-Padroeiras da Europa. Roma, 01/10/1999. Disponível em: <http://w2.vatican.va/content/john-paul-ii/pt/motu_proprio/ documents/hf_jp-ii_motu-proprio_01101999_co-patronesses-europe.html>. Acesso em: 28 out. 2017.

JOÃo PAULO II. Carta Apostólica Salvifici Doloris. Roma, 11/02/1984. Disponível em: <http:// w2.vatican.va/content/john-paul-ii/pt/apost_letters/1984/documents/hf_jp-ii_apl_11021984_salvificidoloris.html>. Acesso em: 28 out. 2017.

JOÃO PAULO II. Homilia na Cerimônia de Canonização de Edith Stein. Roma, 11/10/1998. Disponível em: <http://w2.vatican.va/content/john-paul-ii/pt/homilies/1998/documents/hf_jp-ii_ hom_11101998_stein.html>. Acesso em: 28 out. 2017.

KOVÁCS, M.J. Morte e desenvolvimento humano. São Paulo: Casa do Psicólogo, 1992.

SCIADINI, Patrício (Org.). Edith Stein, na força da cruz: seleção de textos de Waltraud. São Paulo: Cidade Nova, 2008.

STEIN, Edith. A ciência da cruz. Estudo sobre São João da Cruz. São Paulo: Loyola, 1988.

STEIN, Edith. Ser finito y ser eterno. Ensayo de una ascensión al sentido del ser. México: Fondo de Cultura Económica, 1996.

STEIN, Edith. Escritos autobiográficos y cartas. Madrid: Editorial de Espiritualidad/Vitoria; Monte Carmelo: Ediciones El Carmen/Burgos, 2002. (Obras Completas, 1). 